\title{
RESIDUAL STRENGTH AND POST-CRACKING BEHAVIOUR OF GLASS WOOL FIBRE-REINFORCED CONCRETE EMBEDDED WITH STEEL REINFORCEMENT
}

\author{
Olutoge Festus ${ }^{1 *}$ and Ogundeji D. Oluwaseun ${ }^{2}$ \\ ${ }^{1}$ Faculty of Engineering, The University of the West Indies, Trinidad \\ ${ }^{2}$ Faculty of Technology, University of Ibadan, Nigeria \\ ${ }^{1}$ Email: festus.olutoge@ sta.uwi.edu*(Corresponding author) \\ ${ }^{2}$ Email: oluwaseunogundeji@gmail.com
}

\begin{abstract}
This study aims to experimentally investigate and present the impact of glass wool fibre (GWF) on the residual flexural strength (RFS) for conventionally reinforced concrete elements by carrying out RFS test on concrete prism specimens. Additional tests, compressive and splitting tensile strength tests were also conducted on cube and cylinder specimens respectively to further examine the effect of the fibre on concrete. Twenty cubes of size 100 by 100 by $100 \mathrm{~mm}$, twelve cylinders of size 100 by $200 \mathrm{~mm}$ and two sets of twelve prisms of size 100 by 100 by $400 \mathrm{~mm}$ each with and without steel reinforcement (SR) were cast and then cured by water immersion for 28 days after which they were made to undergo compressive, splitting tensile and RFS test (using 3-Point Bending). The GWF content added ranges from $0.00 \%$ to $1.00 \%$ for four different mixes used.

The results showed a significant percentage increase of $20.83 \%$ in tensile strength with $0.50 \%$ fibre content and marginal increase of $0.26 \%$ in compressive strength with $0.25 \%$ fibre dosage. The study also showed that combination of conventional SR and GWF in concrete resulted in enhanced residual strength. It was observed that the average RFS of glass wool fibre-reinforced concrete (GWFRC) with and without SR increased with increasing fibre contents up to $0.50 \%$ before a decline in the strength was observed with $1.00 \%$ fibre dosage.

It was evident that the effect of SR dominated that of GWF in concrete but the combined effect in terms of post-cracking behaviour and strength was favourable to the long-term performance of concrete. Hence, the use of both SR and GWF in concrete should be given more consideration in concrete industry because of the possibility of improved residual flexural strength and as their synergic tensile properties could have positive impact on service life of concrete structures.
\end{abstract}

Keywords: Glass wool fibre, Concrete structures, Residual flexural strength, Postcracking behaviour, Service life.

https://doi.org/10.47412/TOOR2405

\section{Introduction}

All reinforced concrete structures are composite materials. According to [1], the tensile strength of concrete is only 10 per cent of the compressive strength. Moreover, because of this, nearly all reinforced concrete structures are designed on the assumption that the concrete does not resist any tensile forces. Steel reinforcement used in concrete is designed primarily to carry these tensile 
forces, which are transferred by bond between the interface of the two materials [1]. In addition, fibres are materials known to be excellent in tension. As submitted in [2], several types of fibres have been used to reinforce concrete, the choice of which varies from synthetic organic materials such as polypropylene or carbon, synthetic inorganic such as steel or glass, natural organic such as cellulose to natural inorganic such as asbestos. Fibres are short and closely spaced and as well distributed through given cross section unlike SR which are continuous and only placed where required in concrete matrix [2].

As pointed out in [3], conventional steel reinforced concrete structure is known to be susceptible to cracking in the tension region as a result of low tensile strength properties of concrete, which can impair long-term performance of the concrete structure. It was stated in [4] that fibres, material with excellent tensile properties, are chiefly known to contribute majorly to the post cracking response of concrete by bridging the cracks and also provide resistance to crack opening in concrete structures. However, to prevent potential failure, there is a need to determine the loadcarrying capacity existing in a potentially cracked concrete structure all through its expected years of service.

Concrete, as one of the most commonly used construction materials in the world, is known to possess several remarkable properties. Apart from the fact that it can be cast in different shapes, it also has high compressive strength, low thermal and electrical conductivity, stiffness, and low toxicity and combustibility [2]. Conversely, it has deficiencies, not least of which is its susceptibility to fail under tensile loads due to its brittle nature. This and other deficiencies can now be improved by adopting a new concrete technology- fibre reinforced concrete (FRC) [5].

FRC is a concrete that contains fibrous material which is believed to improve the structural integrity of the concrete. It was clearly indicated in [2] that fibres can control cracking more efficiently due to their tendency to be more closely spaced than conventional reinforcement. However, fibre used as concrete reinforcement is not a substitute for conventional reinforcement. From structural point of view, they both have different roles to play in advanced concrete technology, and there are many applications in which both fibres and continuous reinforcing steel bars should be used [6].

There is a tendency for concrete structure to experience microcracks when fully loaded. At service, it was stated in [7] that concrete composite structure will carry increasing loads after the first cracking of the concrete matrix if the pull-out resistance of the fibres at first crack is greater than the load at first cracking. At the cracked section, the matrix does not resist any tension and the fibres carry the entire load taken by the composite. With an increasing load on the composite, the fibres will tend to transfer the additional stress to the matrix through bond stresses leading to multiple cracking. This process of multiple cracking will continue until either fibres fail or the accumulated local debonding leads to fibre pull-out.

In concrete technology, most often, fibred concrete is combined with conventional steel reinforcement bar but still the full potential of the interaction is not fully utilized in practice. In addition, through experiments, fibres have proven to enhance the ultimate performance of concrete structures with lower amounts of conventional reinforcement [8]. Fibres improve the post-cracking behaviour of the concrete matrix, which mainly improves the behaviour in serviceability limit state (SLS) regarding crack widths, crack spacing and deflection (due to increased flexural stiffness). However, the ability to bridge cracks and improve the load carrying capacity widely depends on the amount of fibres mixed into the concrete. Unfortunately, due to uncertainties in fibre 
distribution and fibre orientation it is hard to utilize the full capacity of the fibres in design. It is therefore very common that conventional reinforcement is used for the ultimate limit state (ULS) capacity (referenced in [9]), which has a known placement in the structure and has a more efficient internal lever arm.

As earlier stated, concrete is known to exhibit some microcracks even before it is subjected to any external loadings especially at the coarser aggregates-mortar interface. Some of these microcracks are caused by shrinkage and thermal expansion/deformation of the mortar. These microcracks influence the mechanical behaviour of concrete, and their propagation during loading contributes to the non-linear behaviour at low stress levels and causes volume expansion near failure. When the concrete is loaded, microcracks develop during the loading process because of the difference in stiffness between aggregates and mortar, and since the aggregate-mortar interface usually constitutes the weakest link in the concrete composite system [8]. Thus, it is chiefly believed that the effect of fibres in concrete is to primarily improve toughness and post-cracking behaviour rather than increasing the strength of concrete.

As mentioned above, the major reinforcing effect of fibres in most fibre-reinforced concrete is experienced after the first concrete matrix cracking. The main advantage of adding fibres to concrete is that they improve the post-cracking behaviour and toughness (residual tensile strength) in combination with a large tensile strain. In other words, fibres improve concrete capacity of transferring stresses after matrix cracking and the tensile strains at rupture. The load carrying capacity of a cracked concrete composite structure is the residual strength of that structure. Thus, the residual strength exhibited by fibre-reinforced-concrete is a direct consequence of crack bridging in the concrete which includes aggregate bridging and fibre bridging.

\section{Materials and Methods}

This chapter discusses the experimental programme in terms of the constituent materials used in casting the specimens and the experimental arrangement conducted in this study. It describes the specifications of the specimens, mix design and the various laboratory tests carried out as well as how the tests were planned and executed.

The constituents'materials used in this research work were sourced locally and are hereinafter described:

- Cement: Elephant brand cement of grade $32.5 \mathrm{~N}$ conforming to [10] was used as binder.

- Aggregates: Both fine and coarse aggregates were used. River sand with particle sizes ranging from $0.10-2.36 \mathrm{~mm}$ was used as fine aggregate while machine crushed granites of size not greater than $12.5 \mathrm{~mm}$ ( $1 / 2$ inches) was used as coarse aggregate conforming to [11].

- Potable water: The potable water conforming to [12] was used in preparing the concrete mixes with the adoption of water-cement ratio 0.5 for efficient workability due to the fibre content.

- Steel reinforcement: A total quantity of 48 high yield $10 \mathrm{~mm}$ diameter steel reinforcement bars each of length $380 \mathrm{~mm}$ was used in the study. Mild yield $06 \mathrm{~mm}$ diameter steel bar was used as links. 
- Fibre: The fibre used in the present investigation was glass wool fibre having properties described in Table 1 below and as gathered from Man-made vitreous fibres: nomenclature, chemical and physical properties. Stamford, CT, Thermal Insulation Manufacturers' Association (referenced in [13]).

Table 1: Properties of GWF

\begin{tabular}{|c|c|}
\hline Fibre type: & Glass wool fibre \\
\hline Modulus of elasticity: & 55 \\
\hline Specific gravity: & 2.68 \\
\hline Length (mm): & 14 \\
\hline Diameter (micron): & 8 \\
\hline Aspect ratio: & 1750 \\
\hline Effect of temperature: & Non-combustible \\
\hline
\end{tabular}

\subsection{Mix design method}

Grade 20 concrete was designed and water/cement ratio 0.5 was used and maintained for all the mixes to enhance workability due to the concrete fibre content. GWF contents $0.25 \%, 0.50 \%$ and $1.00 \%$ were applied separately in each of the concrete batches. Plain concrete mix of GWF content $(0.00 \%)$ was adopted as the control experiment. Table 2 shows the equivalent quantity by weight of each component of the concrete mix per $0.03540 \mathrm{~m}^{3}$ and per cubic meter. Mix ratio 1:2:4 was used throughout the experimental studies. The volume of concrete per mix was calculated and 5\% of this was added to cater for wastage during mixing and transferring of the fresh concrete.

Table 2: Final mix proportions

\begin{tabular}{|l|c|c|c|c|}
\hline \multicolumn{1}{|c|}{ Quantities } & Cement $(\mathrm{Kg})$ & Fine Aggre. $(\mathrm{Kg})$ & $\begin{array}{c}\text { Coarse Aggre. } \\
(\mathrm{Kg})\end{array}$ & Water (Ltr.) \\
\hline Per $0.03540 \mathrm{~m}^{3}$ mix & 12.14 & 24.28 & 48.56 & 6.07 \\
\hline Per $\mathrm{m}^{3}$ of concrete & 360 & 720 & 1440 & 180 \\
\hline
\end{tabular}

\subsection{Specifications of specimens}

There are 56 specimens in total that were cast and tested. The specimens comprise 20 cubes, 12 cylinders, and 24 prisms. Table 3 gives the breakdown of all the 56 specimens. It shows the number of specimens to be cast per mix with their various fibre contents. Thus, 14 specimens were to be cast per mix which include 5 cubes, 3 cylinders, 3 prisms without reinforcement bars (nB) and 3 prisms with reinforcement bars $(\mathrm{wB})$. Figure 1 below shows the steel reinforcement used while Fig. 2 is the cross sections of the beam specimens embedded with steel reinforcement showing the reinforcement detailing. 


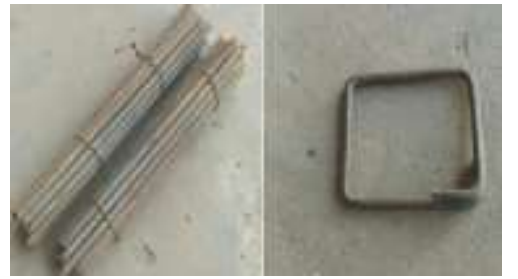

Figure 1: 10mm SR and 6mm square link
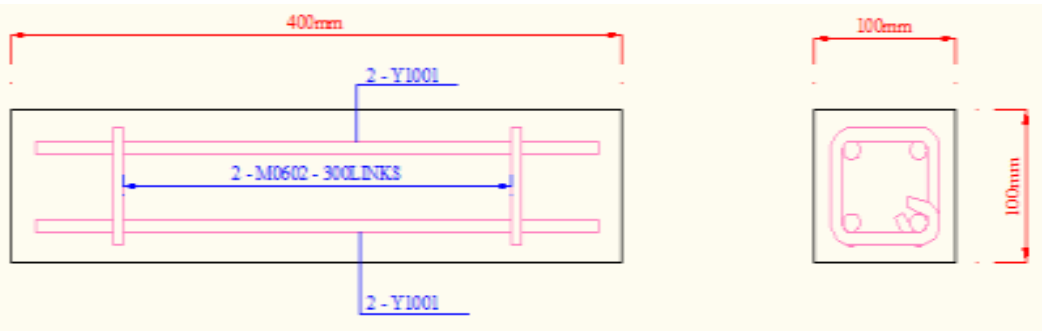

Figure 2: Cross sections of beam specimens with SR Table 3: Specimens breakdown

\begin{tabular}{|c|c|c|c|c|c|}
\hline \multirow{2}{*}{ Specimen } & \multicolumn{4}{|c|}{ Varying Percentages of GWF Contents } & \multirow[b]{2}{*}{ Total } \\
\hline & $0.00 \%$ & $0.25 \%$ & $0.50 \%$ & $1.00 \%$ & \\
\hline Cubes & 5 & 5 & 5 & 5 & 20 \\
\hline Cylinders & 3 & 3 & 3 & 3 & 12 \\
\hline Prisms (nB) & 3 & 3 & 3 & 3 & 12 \\
\hline Prisms (wB) & 3 & 3 & 3 & 3 & 12 \\
\hline No. per mix & 14 & 14 & 14 & 14 & 56 \\
\hline
\end{tabular}

\subsection{Experimental investigation}

The various laboratory tests carried out on the hardened concrete specimens after curing by water immersion for 28 days are hereinafter described:

\subsubsection{Slump test}

This is to check for the consistency and workability of freshly made concrete mix as specified in [14].

\subsubsection{Compressive strength test}

Hardened concrete is excellent in compression and is used mostly to resist compressive stress in most structural applications. This test, in accordance with [15], was carried out on the hardened concrete cube specimens in surface-dried state. The ultimate load $[\mathrm{KN}]$ and the compressive strength in $\mathrm{MPa}$ of the specimens were read directly from the display unit of the testing machine.

\subsubsection{Splitting tensile strength test}

An indirect test used to determine the tensile strength of hardened concrete cylinder specimens. The loading rate $0.940 \mathrm{KN} / \mathrm{sec}$ was applied on the specimen and continued until it reached its ultimate load $[\mathrm{KN}]$ which was read together with the corresponding tensile strength [MPa] from the display unit of the testing machine. However, the splitting tensile strength of each cylindrical specimen can also be computed from the splitting tensile strength formula as provided in [16]. 


\subsubsection{Residual flexural strength test}

Residual strength of a concrete structure is its load carrying capacity when the concrete structure cracks. Plain concrete and fibre-reinforced concrete may behave nonlinearly due primarily to internal micro-cracking before the first overall cracking of the beam; hence, determining first cracking can be rather subjective. In the present study, the residual flexural strength test (using three point bending) was carried out in accordance with [17] on the 24 concrete beam specimens in surface-dried state. This test was carried out in two stages. The first stage was conducted on beam specimens reinforced with glass wool fibre only while the second stage was conducted on beam specimens reinforced with both glass wool fibre and steel reinforcement bar.

With Eq. (1) as given in [17], the average residual strength was determined for each beam using the reloading loads corresponding to some sets of deflections, usually $0.50,0.75,1.00$, and 1.25 $\mathrm{mm}$ obtained from the reloading load-deflection response curves. The test was performed using OKH-600 Digital Display Universal Testing Machine.

$$
\sigma=\left(\frac{P 1+P 2+P 3+P 4}{4}\right) \lambda
$$

Where: $\sigma=$ average residual strength $[\mathrm{MPa}], \quad \mathrm{P} 1+\mathrm{P} 2+\mathrm{P} 3+\mathrm{P} 4=$ sum of reloads at specified deflections $[\mathrm{N}]$

$$
\lambda=\frac{3 L}{2 B D}{ }^{2}
$$

$\mathrm{L}, \mathrm{B}$, and D are respectively the length, breadth, and depth of the beam specimens [mm]

\section{Results and Discussion}

The main area of interest in this research work was to determine the residual flexural strength of GWFRC embedded with and without SR with slight emphasis laid on the post-cracking behaviour. This chapter presented and explicitly discussed the results of various tests conducted in the current study. Discussions of each test are presented in the following subsections.

\subsection{Slump Test Result and Discussion}

The Fig. 3 below shows the average slump values obtained for the four different mixes with their varying fibre contents.

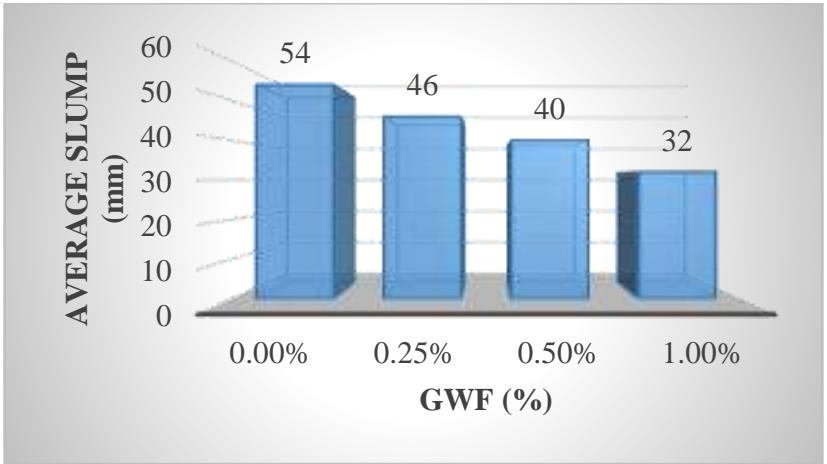

Figure 3: Slump test results of fresh concrete mixes 
From Fig. 3 above, the average slump values range from $54 \mathrm{~mm}$ to $32 \mathrm{~mm}$ which indicates that addition of GWF in freshly made concrete significantly affects the workability and consequently leads to the reduction of slump values in increasing order of GWF contents.

\subsection{Compressive Strength Test Result and Discussion}

The means of the compressive strengths of the various sets of concrete cube specimens with their corresponding GWF contents are hereinafter presented in Fig. 4 below.

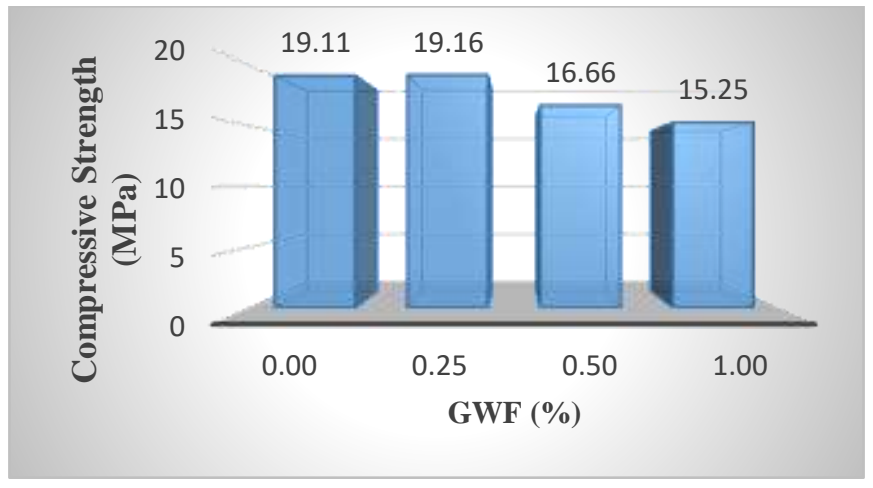

Figure 4: Compressive strength vs. GWF (\%)

From Fig. 4 above, there is variation in compressive strength of the concrete cube specimens for the varying GWF contents used. The compressive strength (19.16 MPa) of concrete cubes with fibre contents $0.25 \%$ was only slightly higher than the compressive strength $(19.11 \mathrm{MPa})$ of the plain concrete by $0.26 \%$ while others were noticeably lower than the control specimens. This implies that increasing GWF content has little or no positive effect on compressive strength except when optimum fibre content is used.

\subsection{Splitting Tensile Strength Test Result and Discussion}

Figure 5 below shows the splitting tensile strength values obtained for the concrete cylindrical specimens.

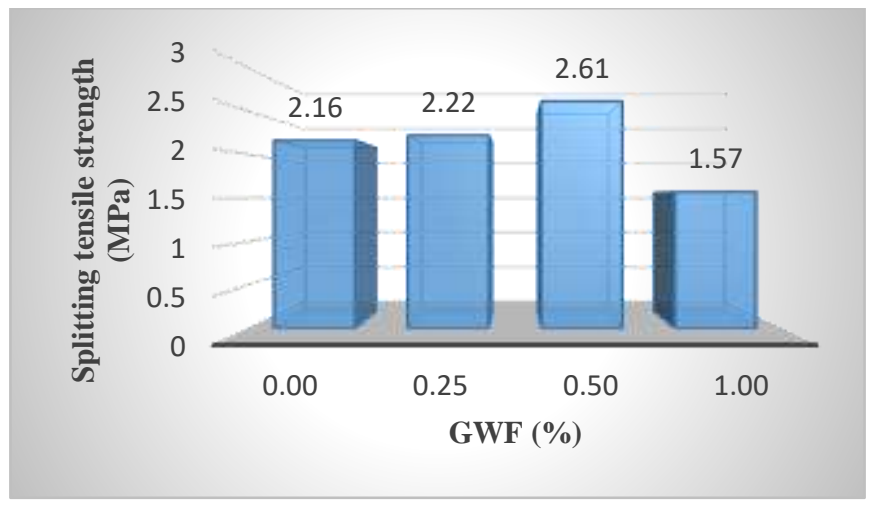

Figure 5: Splitting tensile strength vs. GWF (\%)

From Fig. 5 above, the splitting tensile strength obtained for plain concrete was $2.16 \mathrm{~N} / \mathrm{mm}^{2}$ while the value obtained for GWFRC with $0.25 \%$ fibre content was $2.22 \mathrm{~N} / \mathrm{mm}^{2} ; 2.61 \mathrm{~N} / \mathrm{mm}^{2}$ for $0.50 \%$; and $1.57 \mathrm{~N} / \mathrm{mm}^{2}$ for $1.00 \%$. Consequently, $2.78 \%$ and $20.83 \%$ increase were observed in splitting tensile strength with $0.25 \%$ and $0.50 \%$ GWF contents respectively. This indicates that increasing 
the fibre contents to an optimum percentage enhances the tensile strength by delaying formation of cracks before the ultimate failure of the concrete specimens. Conversely, noticeable reduction in splitting tensile strength was observed with $1.00 \%$ GWF content which implies that too much increase in GWF content more than optimum percentage in concrete may lower the splitting tensile strength of concrete.

\subsection{Flexural Strength Test Result and Discussion}

The residual flexural strength result and analysis presented in this section are highly dependent on the correct identification of first cracking in each beam test. The first cracking physically observed on the beam specimen was quite clear. The initial loading data and reloading data obtained and the average reloading loads (ARL) deduced from the reloading load - deflection response curves for GWFRC beam specimens without SR are presented in Table 4 while those with SR are presented in Table 5 respectively.

Table 4: Initial loading and reloading data (without SRB) at age 28 days

\begin{tabular}{|c|c|c|c|c|c|c|c|}
\hline \multirow{2}{*}{$\begin{array}{c}\text { GW } \\
\text { F } \\
(\%)\end{array}$} & $\begin{array}{c}\text { Peak } \\
\text { Load } \\
(\mathrm{KN})\end{array}$ & $\begin{array}{c}\text { Initial loading } \\
\text { Deflection } \\
(\mathrm{mm})\end{array}$ & $\begin{array}{c}\text { Peak Load } \\
\text { Strength } \\
(\mathrm{MPa})\end{array}$ & $\begin{array}{c}\text { Load } \\
(\mathrm{KN} \\
)\end{array}$ & $\begin{array}{c}\text { Reloading } \\
\text { Deflectio } \\
\mathrm{n}(\mathrm{mm})\end{array}$ & $\begin{array}{c}\text { Average } \\
\text { Reloadin } \\
\text { g Load- } \\
\text { ARL } \\
(\mathrm{KN})\end{array}$ & $\begin{array}{c}\text { Averag } \\
\mathrm{e} \\
\text { Residua } \\
1 \\
\text { Strengt } \\
\mathrm{h} \\
(\mathrm{MPa})\end{array}$ \\
\hline 0.00 & 20.36 & 3.26 & 12.22 & 9.98 & 3.41 & 9.90 & 5.94 \\
\hline 0.25 & 20.68 & 5.45 & 12.41 & $\begin{array}{c}12.3 \\
1\end{array}$ & 5.70 & 10.20 & 6.12 \\
\hline 0.50 & 23.28 & 5.16 & 13.97 & $\begin{array}{c}14.4 \\
6\end{array}$ & 5.28 & 10.25 & 6.15 \\
\hline 1.00 & 18.28 & 5.96 & 10.97 & $\begin{array}{c}10.0 \\
2\end{array}$ & 6.18 & 7.13 & 4.28 \\
\hline
\end{tabular}

Here, ARL is the average of the reloading loads corresponding to 0.5, 0.75, 1.00, and 1.25mm deflections from reloading curves. 
Table 5: Initial loading and reloading data (with SRB) at age 28 days

\begin{tabular}{|c|c|c|c|c|c|c|c|}
\hline \multirow{2}{*}{$\begin{array}{c}\text { GW } \\
\text { F } \\
(\%)\end{array}$} & $\begin{array}{c}\text { Peak } \\
\text { Load } \\
(\mathrm{KN})\end{array}$ & $\begin{array}{c}\text { Peak Load } \\
\text { Deflection } \\
(\mathrm{mm})\end{array}$ & $\begin{array}{c}\text { Peak Load } \\
\text { Strength } \\
(\mathrm{MPa})\end{array}$ & $\begin{array}{c}\text { Load } \\
(\mathrm{KN})\end{array}$ & $\begin{array}{c}\text { Deflecti } \\
\text { on (mm) }\end{array}$ & $\begin{array}{c}\text { Average } \\
\text { Reloading } \\
(\mathrm{KN})\end{array}$ & $\begin{array}{c}\text { Average } \\
\text { Residual } \\
\text { Strength } \\
(\mathrm{MPa})\end{array}$ \\
\hline 0.00 & 54.04 & 5.96 & 32.42 & 44.20 & 10.80 & 18.20 & 10.92 \\
\hline 0.25 & 56.19 & 7.08 & 33.71 & 46.02 & 10.36 & 22.80 & 13.68 \\
\hline 0.50 & 54.36 & 6.18 & 32.62 & 44.75 & 9.54 & 23.95 & 14.37 \\
\hline 1.00 & 45.12 & 6.73 & 27.07 & 35.63 & 7.51 & 17.50 & 10.50 \\
\hline
\end{tabular}

Here, ARL is taken as the reloading load corresponding to $1.25 \mathrm{~mm}$ deflection from reloading curves.

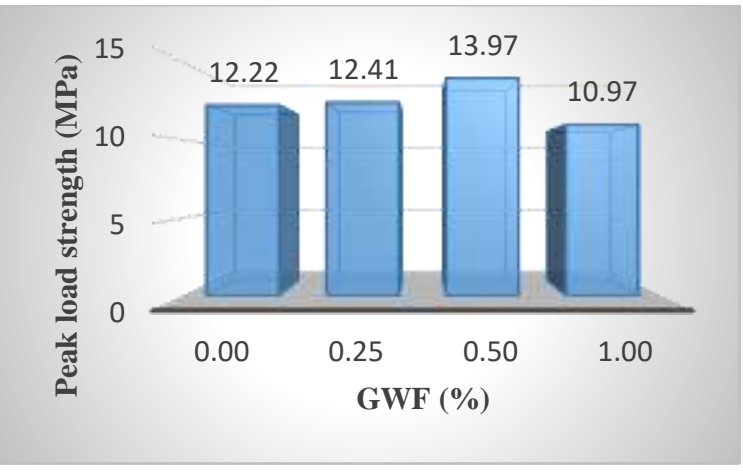

Figure 6: PLS vs. GWF (\%) (Without SR)

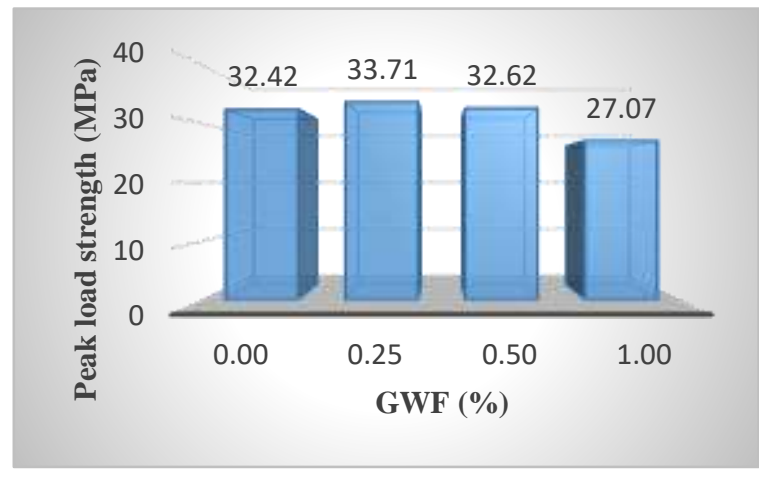

Figure 8: PLS vs. GWF (\%) (With SR)

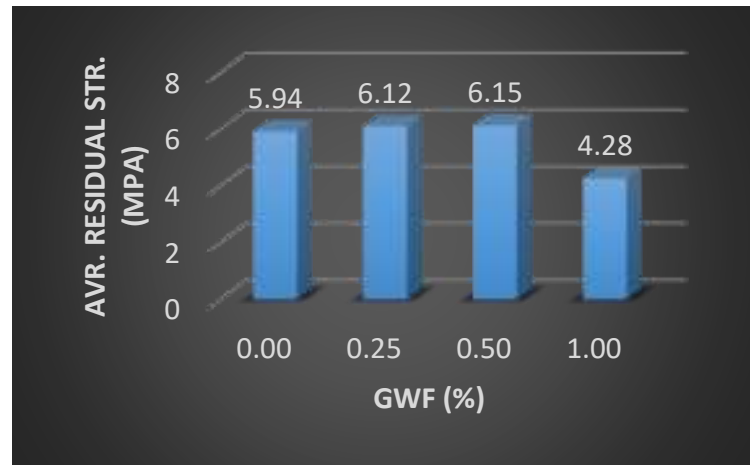

Figure 7: ARS vs. GWF (\%) (Without SR)

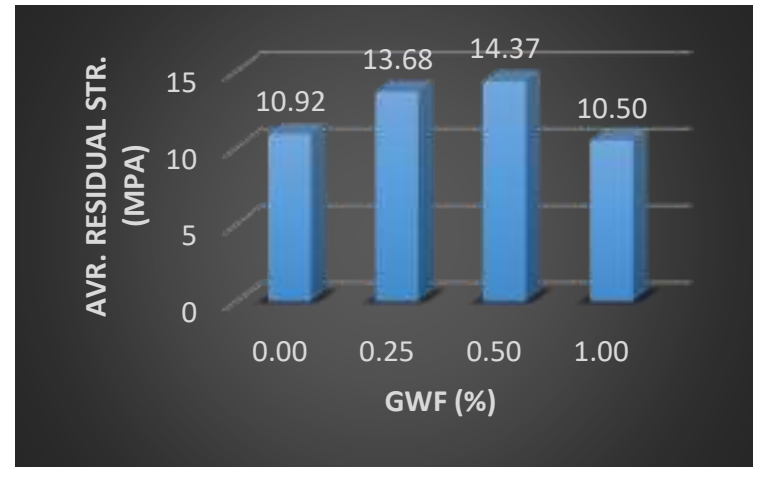

Figure 9: ARS vs. GWF (\%) (With SR)

From Table 4 and Fig. 6, the peak load strengths are $12.22 \mathrm{~N} / \mathrm{mm}^{2}, 12.41 \mathrm{~N} / \mathrm{mm}^{2}, 13.97 \mathrm{~N} / \mathrm{mm}^{2}$, and $10.97 \mathrm{~N} / \mathrm{mm}^{2}$ respectively for $0.00 \%, 0.25 \%, 0.50 \%$ and $1.00 \%$ fibre contents for the beam specimens without SR at initial loading. In Table 5 and Fig. 8, the peak load strengths are $32.42 \mathrm{~N} / \mathrm{mm}^{2}, 33.71 \mathrm{~N} / \mathrm{mm}^{2}, 32.62 \mathrm{~N} / \mathrm{mm}^{2}$, and $27.07 \mathrm{~N} / \mathrm{mm}^{2}$ respectively for $0.00 \%, 0.25 \%, 0.50 \%$ and $1.00 \%$ fibre contents for the beam specimens with SR also at initial loading. 
In both cases, the strength increases with increasing fibre contents from $0.25 \%$ to $0.50 \%$ but a decline in strength was observed with $1.00 \%$ fibre content. This implies that there is a positive effect of fibre on concrete flexural strength with increasing fibre content up to an optimum content beyond which a negative effect is experienced.

Also from Table 4 and Fig. 7, percentage increase of 3.03\% and 3.54\% were obtained in the average residual strength with $0.25 \%$ and $0.50 \%$ GWF contents respectively for beams without SR while increases of $25.27 \%$ and $31.60 \%$ were obtained for beams with SR for the same fibre contents as shown in Table 5 and Fig. 9. It was observed that the effect of SR dominated that of GWF, hence the former has greater influence on the concrete strength properties compared to the latter. Figure 10 and Fig. 11 show the typical initial loading and reloading load-deflection response curves for both sets of beam specimens.

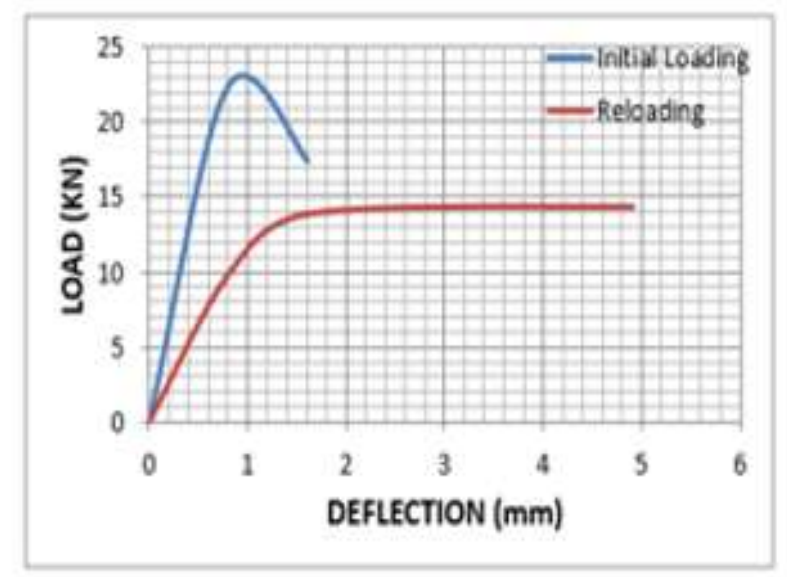

Figure 10: Initial loadReloading load-deflection response curve ( $0.50 \%$ GWF without SR)

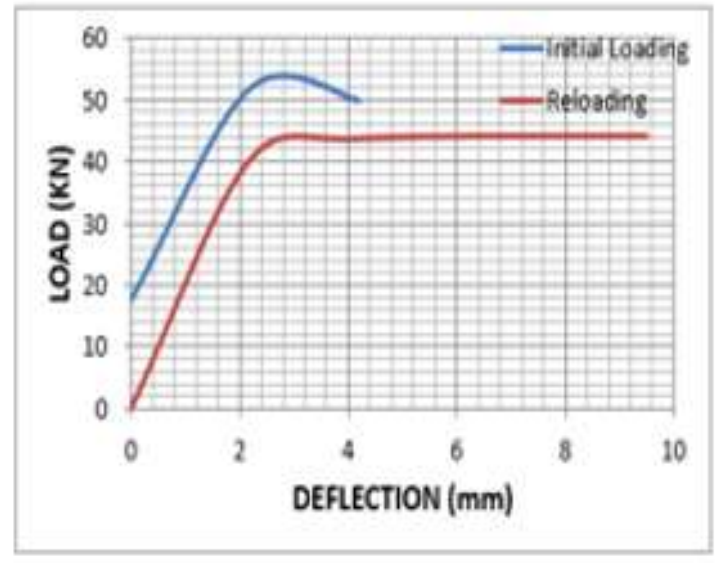

Figure 11: Initial load Reloading load-deflection response curve (0.50\% GWF with SR)

\section{Conclusions}

In the present study, the residual strength of GWFRC embedded with and without steel reinforcement was investigated and the following general conclusions were drawn;

1. Adding GWF to concrete resulted in reduced workability with increasing fibre dosages.

2. Inclusion of GWF marginally improved the compressive strength by $0.26 \%$ at 28 days with $0.25 \%$ GWF content, and slight decline was observed with higher fibre contents.

3. Significant percentage increase of $20.83 \%$ in tensile strength with $0.50 \%$ fibre content was observed at 28 days.

4. Incorporation of conventional SR in GWFRC resulted in enhanced flexural strength thereby improving the concrete performance.

5. It was observed that the effect of SR dominated that of GWF; hence the former has greater influence on the concrete strength properties compared to the latter. 
6. The average residual strengths for both GWFRC with and without SR increased with increasing fibre contents with optimum value- $0.50 \%$ fibre dosage.

\section{References}

[1] B. Mosley, J. Bungey, R. Hulse. 2007. Reinforced Concrete Design to Eurocode 2.

[2] F.A. Olutoge, O.D. Ogundeji. Evaluation of the strength properties of glass wool fibre reinforced concrete. In Third international conference on advances in civil, structural, and mechanical engineering (U.K) - CSM; (2015) pp 95 - 106.

[3] N.J. Delatte. 2007. Concrete pavement design, construction, and performance.

[4] W.S. Supat. 2009. Post-Cracking Characteristics of High Performance Fiber Reinforced Cementitious Composites. The University of Michigan.

[5] J. Beaudoin. Fibre-Reinforced Concrete. National Research Council of Canada, Division of Building Research, Canadian Building Digest 223; February 1982. 5 pp.

[6] Hamid et al. Flexural Behavior of Steel-Fibre-Added-RC (SFARC) Beams with C30 and C50 Classes of Concrete. International Journal of Sustainable Construction Engineering \& Technology, Vol. 3, Issue1; 2012.

[7] Mehta, P.J. Monterio. 2006. Concrete: Microstructure, Properties, and Material, Third Edition. W.P.

[8] I. Löfgren. Fibre-reinforced Concrete for Industrial Construction - a fracture mechanics approach to material testing and structural analysis. Göteborg: Chalmers University of Technology; 2005.

[9] Niclas, H. Christopher. Crack Width Profiles for Fibre-reinforced Concrete Elements with Conventional Reinforcement. Göteborg: Chalmers University of Technology; 2015.

[10] British Standard Code of Practice. BS 12, Portland cement (ordinary and rapid hardening). British Standard Code of Practice; 1996.

[11] British Standard Code of Practice. BS 882, Specification for aggregates from natural sources for concrete; 1992.

[12] British Standard Code of Practice. BS 3148, tests for water for making concrete. Standard Institution. London.

[13] Man-made vitreous fibres: nomenclature, chemical and physical properties. Stamford, CT, Thermal Insulation Manufacturers' Association, 1991.

[14] BS EN 12350-2:2009. Testing Fresh Concrete. Slump-test.

[15] British Standard Code of Practice. BS 1881-116: method for determination of compressive strength of concrete cubes; 1983.

[16] ASTM C496 - 17 Standard test method for splitting tensile strength of cylindrical concrete specimens.

[17] ASTM C1399-07a: Standard Test Method for Obtaining Average Residual-Strength of FiberReinforced Concrete; 2007.

[18] R. Gowri et al. Effect of glass wool fibres on mechanical properties of concrete. International Journal of Engineering Trends and Technology (IJETT); 2013 Volume4 Issue7- Pp 3045. 